\title{
THE IMPACT OF COVID-19 ON RESIDENTIAL CARE SERVICES FOR CHILDREN: A CALL FOR FAMILY-BASED APPROACH IN ALTERNATIVE CARE
}

\author{
Lucia Carriera, Chiara Carla Montà, \& Daniela Bianchi \\ "Riccardo Massa" Department of Human Sciences for Education, University of Milano-Bicocca (Italy)
}

\begin{abstract}
Children's rights and needs are at the center of the United Nations 2030 Agenda for Sustainable Development, where education is viewed as crucial for providing the opportunities for sustainable, peaceful and equitable coexistence in a changing world. Alternative care settings are educational contexts (Tibollo, 2015) that deal with children in vulnerable conditions (UN General Assembly, 2010). For this reason, they can be considered as a sort of "field test" or "magnifying glass" on how the progress in striving to the implementation of the goals is proceeding - no one must be left behind. The 2020 global pandemic provoked an external shock to current socio-economic dimensions of sustainability. Education has been one of the most struck systems - let's think of the 1,6 billion learners that have been affected by school closures (UNESCO, 2020).

With this global framework in mind, the contribution aims at offering a pedagogical reflection on the impact the Covid-19 pandemic is having on children living in residential care centers (RCC).

Worldwide, many RCCs, following the ongoing global pandemic, have been closed with the consequent return of children to their families of origin (CRIN, 2020). This process of deinstitutionalization, however, has not been overseen by rigorous monitoring, leading to increased risks of violence for children. This urges authorities to take carefully planned measures with respect to deinstitutionalisation in light of the COVID-19 pandemic (Goldman, et al., 2020). But Covid-19 is not only a health risk for children in RCCs. Because of the complex impact that the pandemic has had on the lives of children, on one side care responses are required, and on the other psycho-social and educational ones are also crucial (SOS Villaggi dei Bambini Onlus Italy; Save The Children, 2020). In Italy, for example, special guidelines have been drawn up to mitigate the spread of the virus within residential structures, that sometimes are overcrowded (Istituto superiore di sanità; SOS Villaggi dei Bambini Onlus Italia, 2020). In addition, tools have been provided to support the mental health of the children and adolescents that are deprived of opportunities for socialization given the closure of schools. In some cases they are isolated within the services themselves to mitigate the risk of the spread, causing a limitation in the possibility of seeing people outside the institution as their parents.

Covid-19 underlines the urgency of promoting family-based alternative care for children. In particular, this paper aims to read through a pedagogical lens, the European scenario of residential services for children, to explore the impact of Covid-19 in these services; and to promote a family-based approach in alternative care preventing the risk of institutionalization in children welcomed.
\end{abstract}

Keywords: Alternative care, children, covid-19, de-institutionalisation, family-based approach.

\section{Introduction}

The United Nations Convention on the rights of the Child -UNCRC- (1989) emphasizes the right and importance of growing up in a family but, in certain exceptional cases -following the principle of the best interest of the individual child-, as stated in Article 20, it may be needed to resort to alternative care settings, amongst which residential care centers (UN General Assembly, 1989):

«1. A child temporarily or permanently deprived of his or her family environment, or in whose own best interests cannot be allowed to remain in that environment, shall be entitled to special protection and assistance provided by the State.

2. States Parties shall in accordance with their national laws ensure alternative care for such a child. 3. Such care could include, inter alia, foster placement, kafalah of Islamic law, adoption or if necessary placement in suitable institutions for the care of children. When considering solutions, 
due regard shall be paid to the desirability of continuity in a child's upbringing and to the child's ethnic, religious, cultural and linguistic background» (UN General Assembly, 1989, p.6).

In most European UNCRC signatory countries, residential care centers (RCC) are part of the child protection system, that aims at defining a general, legal and practical framework for interventions aiming at protecting children. Residential care centres may be defined as a "broad class of settings where children live full-time, with a view to protecting them from the risks of living with their own families who have been deemed - at least temporarily - unable to adequately cater for their development. Furthermore, residential care settings are invested with an "educational mission", they put in place a nurturing environment for predisposing a personal change in children who have experienced adverse conditions by changing the quality of care and environment in which they live in (Biffi \& Montà, 2020, p.173). These aspects are also emphasized by the United Nations 2030 Agenda for Sustainable Development, that sees educational environments as crucial for providing the opportunities for sustainable, peaceful and equitable coexistence in a changing world.

RCCs aim at pedagogically organizing elements such as space, time, language, body, symbols, all elements that put together characterize the educational experience (Tibollo, 2015), in order to promote the human flourishing of children in particularly vulnerable conditions. For this reason, they can be considered as a sort of "field test" or "magnifying glass" on how the progress in striving to the implementation of the goals is proceeding (Montà \& Sommaruga, 2019).

\section{Family-based approaches in alternative care}

The 2020 global pandemic provoked an external shock to current socio-economic dimensions of sustainability. Residential care settings have been impacted on in different ways as the latest studies report.

The report Transition from Institutional Care to Community-Based Services in 27 EU Member States" declares that:

«In times of the COVID-19 pandemic and lockdowns, (...) the negative aspects of institutionalisation are increasingly blatant and only tend to aggravate with the congregation of a large number of people in one building, and the deprivation of social contacts». (Šiška J, \& Beadle-brown, J., 2020, p.3).

Children in RCCs live in close proximity to each other, unavoidably in close contact (Wang J. et al., 2020) so specific regulations have been drafted to mitigate the risk of contagion within residential facilities. In some cases, children, in fact, have been isolated within the services themselves to mitigate the risk of the spread, causing a limitation in the possibility of seeing people outside the institution as their parents and peers. To this end, in Italy, for example, tools have been provided to support the mental health of the children and adolescents that are deprived of opportunities for socialization (SOS Villaggi dei Bambini Onlus Italia, 2020). When thinking of RCCs as a "magnifying glass" of sustainable development-as they deal with children in vulnerable conditions, the pandemic has exacerbated structural issues within them mining the progress towards the SDGs. RCCS, in fact, are often considered as the last resort and, due to the dominant culture of risk management and protection, high caseloads, the burden of paperwork, the lack of adequate staffing, work modes tend to be procedure-driven and often child unfriendly rather than based on a pedagogical model able to provide a nurturing environment for the flourishing of children's capabilities (Beckett et al., 2007; Horwath, 2010; Winter, 2009). The pandemic put children's health at great risk and, with the aim of protecting them, their needs-rights, that are already in a fragile position, have been definitely "locked-down"-let's think of individualised interventions, respect for the child's well-being and rights, taking into account children's opinions and preferences (UN General Assembly, 2009; Eurochild, 2012).

If on one side children have been locked down in RCCs, on the other side it is RCCs that have been closed down, leading to the return of children to their families of origin. This might seem to be an important step towards the de-institutionalisation process, a fundamental goal in the child protection system (Eurochild, 2020). However, studies (Wilke, N. G., Howard, A. H., \& Goldman, P. (2020) point out that this process of return to biological families of origin has been very sudden and, above all, has not been adequately supervised. In addition, due to measures to contain the risk of the Covid-19 infection, children cannot count on the crucial support of schools or even on in-person visits for family monitoring. Although policies emphasise the importance of ensuring that children remain with their birth families, this return process is very fragile and potentially risky and deserves to be strategically structured and implemented. Some of the main concerns related to this failure to monitor the de-institutionalisation process, listed by the literature, are 1) unresolved antecedents to placement, 2) lack of pre-placement preparation, 3) poverty and unemployment, and 4) education for children and caregivers (Wilke, N. G., Howard, A. H., \& Goldman, 
P., 2020, p. 3). The ongoing global pandemic has further amplified the fragilities of many families, potentially expanding the risk of vulnerability for children in the child protection system.

In this contribution, in line with the current literature on the topic, we suggest to refer to a "family-based approach" when thinking about the deinstitutionalisation process. We have illustrated how potentially risky it is to send children back to their families of origin without adequate intervention and monitoring strategies. In this paper with "family-based approach", we refer both to the work with families of origin and also to a form of alternative care (Save the Children, 2009).

With regard to the first definition, literature for years has been pointing out the importance of firstly, investing in prevention to strengthen parental responsibility, empower the most at risk families and avoid an escalation of problems that will lead to institutionalisation (Eurochild, 2012). For example, by investing in a wide range of services to address problems that arise at different stages such as: family planning, prenatal care, preventing abandonment at birth, early childhood services, out of school programmes, after school care, specialised services and financial support for children with special/ complex needs and so on (Eurochild, 2012, p.18).

When, as reported in this paper, the removal has already taken place, the reunification of the child with the family of origin should be gradual, and also anticipated by continuous communication between the family of origin and the child. This transition should also be accompanied by a supportive strategy, also through networking with services or organisations that have implemented similar programmes and could facilitate this process (Wilke, N. G., Howard, M. H., \& Pop, D., 2020).

Another crucial dimension highlighted in the literature is the need to mitigate the precedents that led to separation from the family of origin, prior to the child's return, including supporting families through economic resilience programmes for example -especially in a period such as the Covid-19 one (Wilke, N. G., Howard, A. H., \& Goldman, P., 2020).

At last, we briefly take into consideration the second definition of "family-based approach" citing Save The Children's report Keeping Children Out of Harmful Institutions. Why we should be investing in family-based care, that defines this approach as:

«A form of alternative care that involves a child living with a family other than his/her birth parents. This includes kinship care, foster care, adoption, kafala (an Islamic form of adoption), and supported child-headed households». (Save the children, 2009. p VI).

This kind of an approach requires, amongst others, specific selection and training for substitute families, the presence of a legal and policy and procedural framework, standards of care planning, professional monitoring and inspection services, technical support from social services (Save the children, 2009).

\section{Conclusion}

When thinking about RCCs as a "magnifying glass" of sustainable development, whose lens has been additionally brought into focus by the Covid-19 pandemic, we suggest the following points of attention.

The first one refers to adopting a "family-based approach" when working with families both in prevention terms - to avoid displacement of children - and in support terms - to empower families for children's return. During the pandemic the return process has not been pedagogically planned, putting at risk children's rights and their human flourishing, in other words the educational intervention that was taking place within the RCC. Moreover, the families of these children, already in vulnerable conditions, have been suddenly and without adequate support been asked to exercise their parental functions in the midst of a global crisis.

When thinking of RCCs, often considered as a last resort and overwhelmed by procedural and organisational issues, we can note that the pandemic has exacerbated these aspects by overemphasizing protection and limiting the rest of children's rights - locking down children in the institutions and adopting ridged sanitary protocols. For this reason, it is urgent to think of these institutions as a pedagogical dispositive (Tibollo, 2015) able to put the child's needs-rights at the heart, through a personalised educational plan - able to consider the return into the family of origin right from reception.

Finally, it is high-time to think and plan of a "family-based approach" intended as an ensemble of forms of alternative care to RCCs, to limit the risks of institutionalization. 


\section{References}

Beckett, C., McKeigue, B., \& Taylor, H. (2007). Coming to conclusions: social workers' perceptions of the decision making process in care proceedings. Child \& Family Social Work, 12(1), 54-63.

Biffi, E., \& Montà, C. C. (2020). Documenting Children in Alternative Care Services: Transitional Spaces Between 'Being Spoken for' and 'Speaking for Oneself'. In M. Alasuutari, H. Kelle, \& H. Knauf (Eds.), Documentation in Institutional Contexts of Early Childhood: Normalisation, Participation and Professionalism (pp. 167-183). Retrieved 18.02.2021, from https://doi.org/10.1007/978-3-65828193-9 9

CRIN (2020). Children in Out-of-Home Care: Lessons from the Pandemic. Retrieved 18.02.2021, from https:/home.crin.org/readlistenwatch/stories/children-in-out-of-home-care-lessons-from-thepandemic?rq= $\operatorname{covid} \% 2019$

Eurochild. (2012). De-institutionalisation and quality alternative care for children in Europe: Lessons learned and the way forward. March, 1-27.

Goldman, P. (2020). The implications of COVID-19 for the care of children living in residential institutions. The Lancet, Child and Adolescence Health, 4(6).

Horwath, J. (2010). See the practitioner, see the child: The framework for the assessment of children in need and their families ten years on. British Journal of Social Work, 41(6), 1070-1087.

Jennifer C. Davidson, Ian Milligan, Neil Quinn, Nigel Cantwell \& Susan Elsley (2017) Developing family-based care: complexities in implementing the UN Guidelines for the Alternative Care of Children, European Journal of Social Work, 20:5, 754-769. doi: 10.1080/13691457.2016.1255591

Montà, C., \& Sommaruga, S. (2019). Children's Participation within Alternative Care Settings: First Findings from a Narrative Literature Review. ECER 2019 Hamburg-The European Conference on Educational Research. Emerging Researcher's Conference. 'Education in an Era of Risk-the Role of Educational Research for the Future'.

Save The Children (2020). Proteggiamo i bambini. Whatever it takes. L'impatto della pandemia sui bambini e sugli adolescenti in Italia e nel mondo. Retrieved 18.02.2021, from https://s3.savethechildren.it/public/files/uploads/pubblicazioni/proteggiamo-i-bambini-whatever-ittakes.pdf

Save the Children. (2009). Keeping Children Out of Harmful Institutions Keeping Children Out of Harmful Institutions. Keeping Children out of Harmful Institutions: Why Should We Be Investing in Family-Based Care.

Šiška J, \& Beadle-brown, J. (2020). Transition from Institutional Care to Community-Based Services in 27 EU Member States: Final report. Research report for the European Expert Group on Transition from Institutional to Community-based Care. Retrieved 18.02.2021, from https://deinstitutionalisationdotcom.files.wordpress.com/2017/11/report-fo-the-ad-hoc_2009.pdf

SOS Villaggi dei Bambini Onlus Italy (2020). SOS Villaggi dei Bambini e COVID-19: Linee guida per il contenimento e mitigazione del rischio COVID-19 in comunità. Retrieved 18.02.2021, from https://www.sositalia.it/getmedia/40df5a82-df7d-4d30-82bd-0ee07ca59e81/LINEE-GUIDA-PERIL-CONTENIMENTO-E-MITIGAZIONE_SOS.pdf

Tibollo, A. (2015). Le comunità per minori. Un modello pedagogico: Un modello pedagogico (Vol. 12). FrancoAngeli.

UN General Assembly (2010). 64/142. Guidelines for the Alternative Care of Children. 53(53), 1-23.

UN General Assembly. (1989). Convention on the Rights of the Child. United Nations, Treaty Series, 1577, 3. Retrieved 18.02.2021, from https://www.refworld.org/docid/3ae6b38fo.html

UNESCO (2020). Global monitoring of school closures caused by COVID-19. Retrieved 18.02.2021, from https://en.unesco.org/covid19/educationresponse.

Wang, J., Yang, W., Pan, L., Ji, J. S., Shen, J., Zhao, K., Ying, B., Wang, X., Zhang, L., Wang, L., \& Shi, $X$. (2020). Prevention and control of COVID-19 in nursing homes, orphanages, and prisons. Environmental Pollution, 266. Retrieved 18.02.2021, from https://doi.org/10.1016/j.envpol.2020.115161

Wilke, N. G., Howard, A. H., \& Goldman, P. (2020). Rapid return of children in residential care to family as a result of COVID-19: Scope, challenges, and recommendations. Child Abuse and Neglect, 110. Retrieved 18.02.2021, from https://doi.org/10.1016/j.chiabu.2020.104712

Wilke, N. G., Howard, M. H., \& Pop, D. (2020). Data-informed recommendations for services providers working with vulnerable children and families during the COVID-19 pandemic. Child Abuse \& Neglect. Retrieved 18.02.2021, from https://doi.org/10.1016/j.chiabu.2020.104642.

Winter, K. (2009). Relationships matter: the problems and prospects for social workers' relationships with young children in care. Child \& Family Social Work, 14(4), 450-460. 